\section{Low-temperature Scanning Electron Microscopy of Frozen Hydrated Apple Tissues and Surface Organisms}

\author{
Stéphane Roy ${ }^{1,2}$, Alley E. Watada ${ }^{1}$, William S. Conway ${ }^{1}$, Eric F. Erbe ${ }^{2}$, \\ and William P. Wergin ${ }^{2}$ \\ U.S. Department of Agriculture, Agricultural Research Service, Beltsville, \\ MD 20705
}

Additional index words. apple, bud, cell wall, complementary imaging, epicuticular wax, fruit, fungus, three-dimensional imaging, Malus domestica

Abstract. Frozen hydrated buds and epicarp of 'Golden Delicious' apple (Malus domestica Borkh.) were observed with a low-temperature, field emission scanning electron microscope (SEM). In addition to observing surface features of these specimens, holders were modified to observe fractured specimens. A modified hinged holder retained both halves of a fractured specimen for examination of the complementary faces of frozen hydrated tissues. Low-temperature SEM avoided artifacts, such as extraction, solubilization, and shrinkage, which are normally encountered with chemical fixation, dehydration, and drying, respectively. The technique allowed observations of well-preserved frozen hydrated structures, such as the platelets of epicuticular wax; loosely associated organisms on plant surfaces, such as spider-mite eggs; delicate structures, such as fungal hyphae; and partially hydrated tissues, such as fruit epicarp and winter bud scales.

During the past 25 years, electron microscopy (EM) has greatly expanded our knowledge about the fine structure of horticultural crops. For example, the transmission electron microscope (TEM) has revealed ultrastructural changes that occurred during fruit ripening (Ben-Arie et al., 1979; Crookes and Grierson, 1983; Laval-Martin, 1974; Masia et al., 1992); the scanning electron microscope (SEM) has provided detailed observations of epicuticular waxes (Bukovac et al., 1981; Faust and Shear, 1972; Glenn et al., 1985) and of the life cycles of several rust fungi (Littlefield and Heath, 1979). Both instruments, the TEM and the SEM, have provided structural information that has helped horticulturists relate ultrastructural changes to physiological processes and understand many of the biological events occurring in horticultural plants. Although EM studies are invaluable, the plant materials examined with these techniques must be subjected to chemical fixation, dehydration, embedding or critical-point drying, and staining or coating. All of these preparation procedures

\footnotetext{
Received for publication 15 June 1993, Accepted for publication 24 Sept. 1993. We are grateful to Robert L. Smiley for helpful discussions and to Christopher Pooley for his photographic assistance in preparing the final plates. Mention of a trademark or proprietary product does not constitute a guarantee or warranty of the product by U.S. Dept. of Agriculture and does not imply its approval to the exclusion of other products that may also be suitable. The cost of publishing this paper was defrayed in part by the payment of page charges, Under postal regulations, this paper therefore must be hereby marked advertisement solely to indicate this fact. ${ }^{1}$ Horticultural Crops Quality Laboratory, Building 002, Beltsville Agricultural Research Center-West. ${ }^{2}$ Electron Microscopy Laboratory, Building 177B, Beltsville Agricultural Research Center-East.
}

have been associated with structural artifacts (Beckett and Read, 1986; Crang, 1988; Jeffree and Read, 1991; Kellenberger et al., 1992; Wergin and Erbe, 1989; Wergin et al., 1988). For example, penetration of chemical fixatives, which may require several hours, has been associated with material extrusion; dehydration with solvents may extract or dissolve cellular constituents; critical-point drying can shrink and distort tissues; and sputter-coating with 20 to $30 \mathrm{~nm}$ of gold-palladium may obliterate fine-structural details. To avoid these problems, examining unfixed hydrated tissues with less coating is highly desirable. However, conventional EM imaging requires high vacuum; therefore, biological samples, which contain as much as $90 \%$ water, would quickly collapse. To avoid collapse, Echlin et al. (1970) described a procedure to examine frozen, fully hydrated specimens in a SEM. Specimens observed in this manner did not collapse because they were inserted and observed on a cryostage operating at temperatures below $-130 \mathrm{C}$ where the vapor pressure of water was not significant. Therefore, sublimation did not occur at a detectable rate. Furthermore, at temperatures below $-130 \mathrm{C}$, recrystallization of pure-water ice does not occur. Wergin and Erbe (1992a) have used this procedure to observe frozen samples that remained stable for several hours.

\section{Materials and Methods}

The present study evaluated the advantages of this technique by installing a standard SEM cryostage on a field emission SEM to observe some frozen, hydrated tissues from apple. An Oxford CT 1500 Cryotrans System (Oxford Instruments, Eynsham, England) was mounted on a Hitachi S-4000 field emission
SEM (Hitachi Scientific Instruments, Mountain View, Calif.) to perform low-temperature manipulations and observations. Field emission SEM permits observation of samples having less coating than is normally required for a conventional SEM (Wergin et al., 1988). 'Golden Delicious' apple specimens consisted of the following: 1) mature healthy fruit harvested from commercial orchards, 2) fruit infected with a fungal pathogen, and 3) vegetative buds removed from orchards during the winter.

Several types of specimen holders were either modified or fabricated for the apple specimens (Fig. 1a-c). One-square-centimeter segments of epicarp and underlying parenchyma were removed from mature fruit and mounted in a complementary holder (upper portion of Fig. 1a) that was originally described by Steere and Erbe (1981) to produce platinum/carbon replicas that could be observed in a TEM. This holder was modified so that it could be firmly attached to a flat holder and inserted into the SEM to observe both halves of the frozen fractured tissue. Other segments of epicarp were mounted on a flat
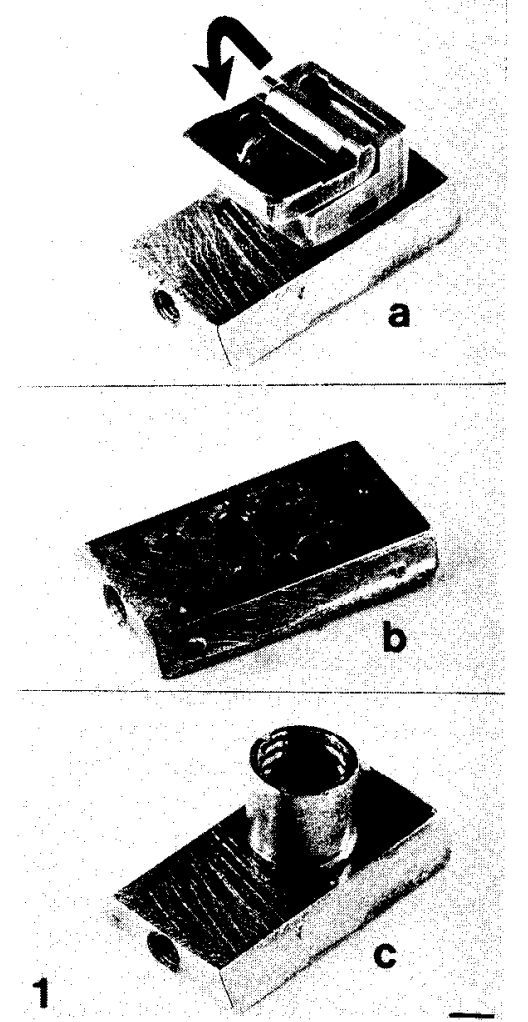

Fig. 1. Specimen holders modified and fabricated for observing apple tissues. (a) Modified complementary holder mounted on a flat holder. A segment of the pericarp was mounted in the cavity of the complementary holder. The arrow illustrates how the holder is opened, which fractures the sample but retains the complementary faces. This entire assembly can then be inserted into the microscope to observe the fractured, frozen, hydrated specimen. (b) Flat holder with multiple mounting holes. (c) Flat specimen holder containing a threaded cylindrical ring. The ring maintained the bud in a vertical position and allowed cross fracture of the tissues. Bar $=2 \mathrm{~cm}$. 
specimen holder (Fig. 1b). Buds were mounted vertically on a specimen holder containing a threaded cylindrical ring that was attached to a flat specimen holder (Fig. 1c). All specimens were mounted to holders with a cryo-adhesive (Tissue Tek; Miles Scientific, Naperville, Ill.).

Each holder was rapidly plunge-frozen in liquid nitrogen and cryo-transferred under vacuum to scold stage in the prechamber of the cryosystem. To examine internal tissues, frozen specimens were fractured inside the Oxford prechamber either with a precooled scalpel blade or by lifting and rotating the fracture arm of the complementary holder through any $180^{\circ}$ angle. The latter action, which is similar to opening a book, separates the two halves of the holder by flipping the upper half, thereby exposing both complementary faces of the freeze-fractured sample.

The frozen-fractured specimens were etched in the prechamber by raising the temperature of the stage to $-90 \mathrm{C}$ to remove the surface-water ice through sublimation. The specimens were then sputter-coated with Pt in the prechamber and then transferred to the cryo-stage in the SEM for observation.

Locating and matching the two complementary areas of the fractured samples were facilitated by using the raster rotation feature of the microscope to rotate the beam until the longitudinal axis of the opened, complementary holder was oriented either parallel or perpendicular to the horizontal axis of the viewing cathode ray tube. After an area on one-half of the holder was viewed and photographed, the stage was systematically moved to the other half of the holder. This procedure greatly facilitated locating the complementary areas of a fractured specimen so that it could be observed, compared, and photographed efficiently.

\section{Results}

By using the flat holder (Fig. 1b), square areas $\left(3 \mathrm{~cm}^{2}\right)$ or elongate $(10 \mathrm{~cm})$ segments of the apple fruit could be observed. The epicuticular wax, which appeared relatively smooth on a mature fruit, exhibited numerous surface cracks (Fig. 2). The preparation procedure did not distort the surface. Moreover, cryo-fixation seemed to retain the structure of wax platelets, which would have been altered or removed by solvents during conventional dehydration. Shrinkage, which frequently characterizes specimens that are air-dried, criticalpoint-dried, or freeze-dried, was not observed.

The apple surface that was infected with Penicillium expansum Link exhibited delicate hyphae in their normal growth state (Fig. 3). Because these samples were not immersed and transferred in fixatives or solvents, loosely associated structures such as hyphae or spores were easily maintained so that the plant-pathogen relationships might be investigated.

The holders and the cryostage did not prevent the specimens from being tilted, thus stereo pairs could be recorded and studied (Figs. 3 and 4). In standard SEM photographs, the complex image of a three-dimensional specimen, which may lie on a tilted stage, is

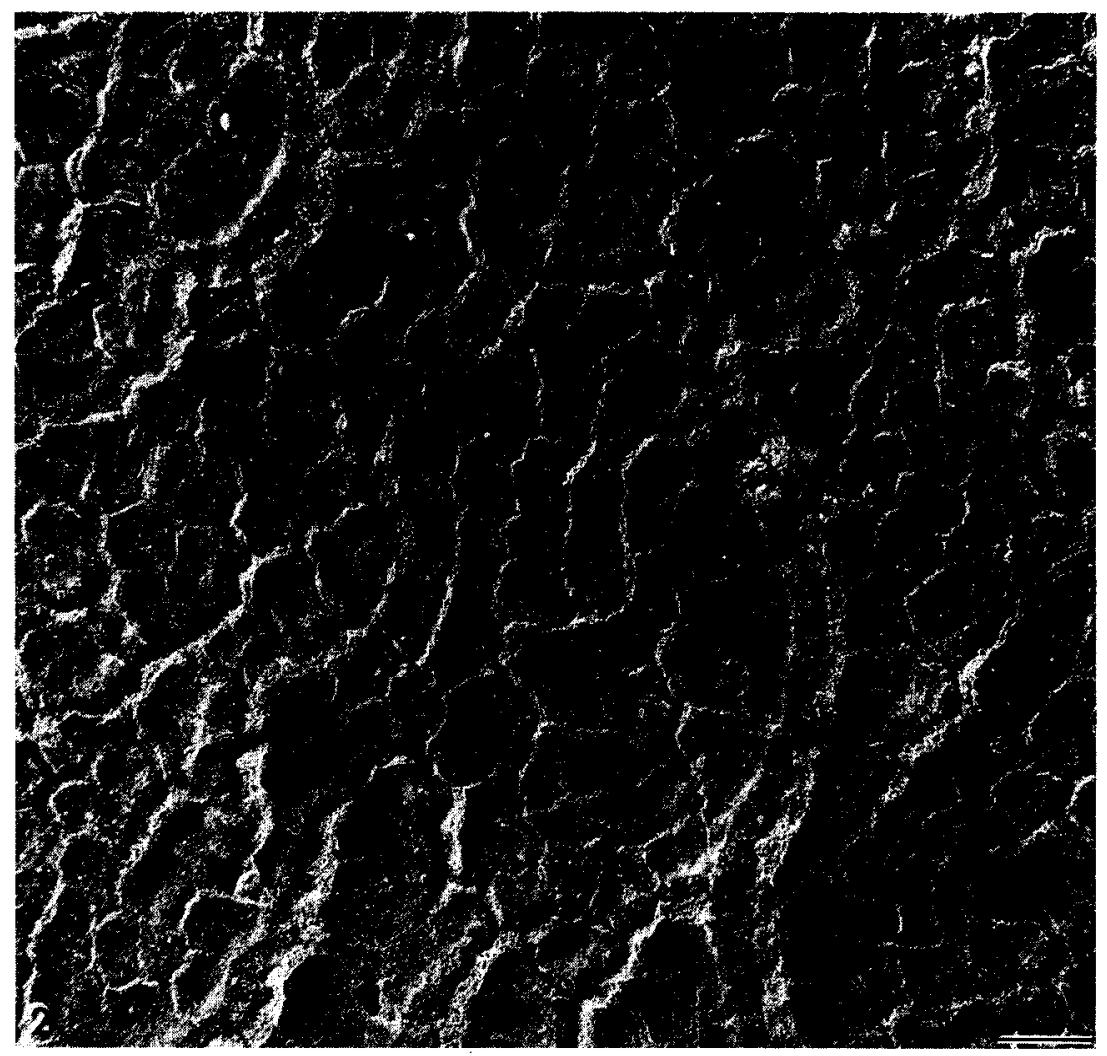

Fig. 2. Epicuticular wax surface of apple fruit examined with low-temperature scanning electron microscope. The network of cracks (arrows) is characteristic of the older expanding fruit. Bar $=150 \mu \mathrm{m}$.

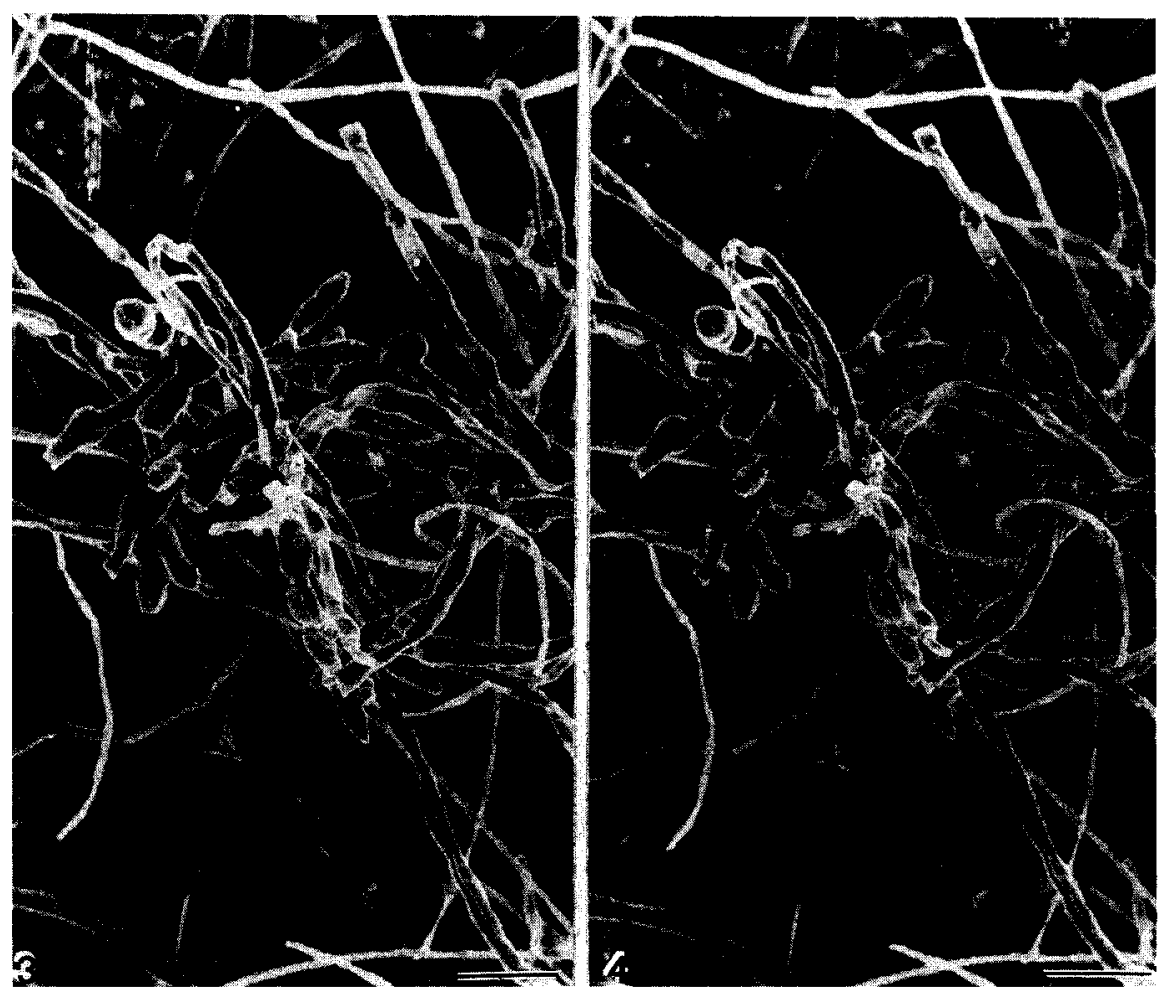

Figs. 3-4. Complementary stereo images of the surface of apple fruit infected by a fungal pathogen, To attain the three-dimensional view, place a stereo viewer on the micrographs so that the left and right lenses are aligned above the left and right images, respectively. Alternatively, a three-dimensional view can be achieved without a viewer by entraining the left and right eyes on the left and right figures, respectively. Bar $=20 \mu \mathrm{m}$. 
projected and recorded onto a horizontal, flat, two-dimensional film. Observation and analysis of single two-dimensional prints can frequently lead to misinterpretations because of the foreshortened dimensions, distorted shapes, or spatial confusion that results from overlapping structural features. These visual artifacts are easily avoided by recording a second image that contains the parallax information necessary for three-dimensional viewing (Wergin and Pooley, 1988). Figures 3 and 4 constitute a stereo pair in which the three-dimensional features of the specimen can be studied. The added information gained from this technique can be used to elucidate the true structural features of a sample and, if necessary, can be used to obtain accurate quantitative measurements of structural features (Wergin, 1984).

Using the complementary portion of the holder (Fig. 1a) allowed the frozen fruit pericarp to be fractured, but it retained both halves of the fractured sample. Further, when the complementary holder was attached to a flat holder, the entire assembly could be inserted into the microscope. The opened halves of the holder exposed the two complementary faces of the fractured specimen, which could then be observed, compared, and photographed (Figs. 5 and 6). The fracture plane did not follow a single path across the pericarp. Alternatively, pericarp tissue fractured at different planes within the apoplast and within the vacuole of a cell. This fortuitous feature frequently assisted in distinguishing the cell walls and intercellular spaces from the cytoplasm. The advantage of using complementary pairs was that examination and study were not limited to a single fractured image of the sample; the opposing half of the fractured specimen was also available for comparison and analysis. Complementary faces illustrated the interconnections of the apoplastic system in apple fruit more convincingly. They are invaluable for distinguishing contaminating artifacts from true structural features.

Simple freeze-fracture of winter vegetative buds revealed the spatial organization of the bud scales and young leaves (Fig. 7), which are covered by numerous hairs. At higher magnification, the parenchymatous tissue of the outer scales was visible (Fig. 8). The cells retained their shape during sublimation; no cellular collapse or deformation was present.

All tissues, the pericarp (Figs. 5 and 6) and bud scales (Fig. 8), had fully turgid cells. The cryotechnique did not appear to alter the degree of hydration that a tissue exhibited in vivo. This condition would be influenced by chemical fixation in aqueous solutions. Therefore, cryofixation would allow one to study a phenomenon such as winter kill in floral and vegetative buds by observing where ice crystal formation naturally occurred and what tissues, cells, and membranes were damaged as a result.

Micromanipulations can be performed on frozen samples. An intact spider mite egg (Panonychus sp.) that was laid on the surface of the scales (Fig. 9) was photographed, and then the holder was moved to the prechamber, fractured with a precooled blade, again sputter-coated, and reinserted into the SEM for further observation. The fracture revealed the internal organization of the egg (Fig. 10).

\section{Discussion}

The general advantages of low-temperature SEM, as opposed to conventional electron microscopic techniques, have been discussed previously (Beckett and Read, 1986; Echlin et al., 1970; Jeffree and Read, 1991; Read and Jeffree, 1991; Wergin and Erbe, 1989, 1991, 1992b). Our experience with the apple samples that we studied indicates that this technique also 1) allowed observation of apple tissues with vastly different states of hydration, e.g, pericarp vs. winter buds; 2) permitted large areas of complementary fractured faces to be examined; 3 ) preserved tenuous associations (mites) and delicate structures (fungal hyphae); and 4) was nondestructive, which allowed further observations after fracture or other micromanipulations. In addition, using a field emission SEM in the present study enabled observation of samples with less coating than is required for conventional SEM examination (Wergin et al., 1988).

Three disadvantages have been associated with low-temperature SEM: specimen storage, contamination, and ice crystal damage. Although storing frozen samples is less convenient than storing dried samples, the frozen hydrated fruit cuticle examined in the present study was observed in the SEM, stored for several weeks in liquid nitrogen, and then reexamined in the SEM. No detrimental changes or artifacts were observed after storage. Therefore, storing frozen specimens was possible even though it was more tedious and awkward than storing dried specimens.

Contamination is more serious with frozen
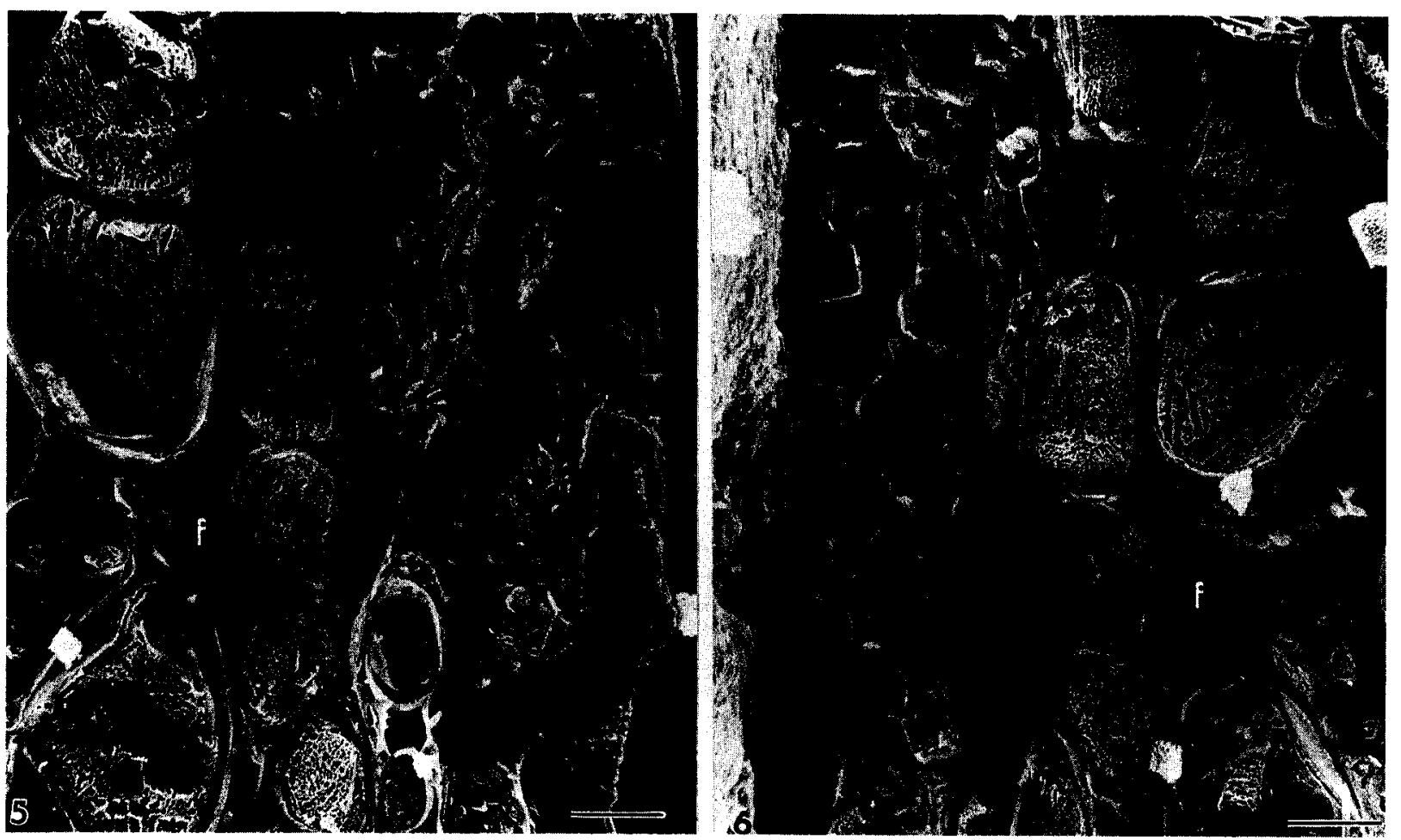

Figs. 5-6, Complementary cross fractures through the frozen pericarp illustrating several hypodermal layers. The fracture does not follow a single flat horizontal plane; alternatively, many of the cellular components fracture at unique, distinct planes. Because the larger cells were more hydrated, ice crystals formed in the cytoplasm; subsequent sublimation of the ice resulted in numerous small holes or openings visible in the cytoplasm. c, Cuticle; cw, cell wall; e, epidermis; hy, hypodermic; i, intercellular space; $p$, parenchyma. Bar $=16 \mu \mathrm{m}$. 


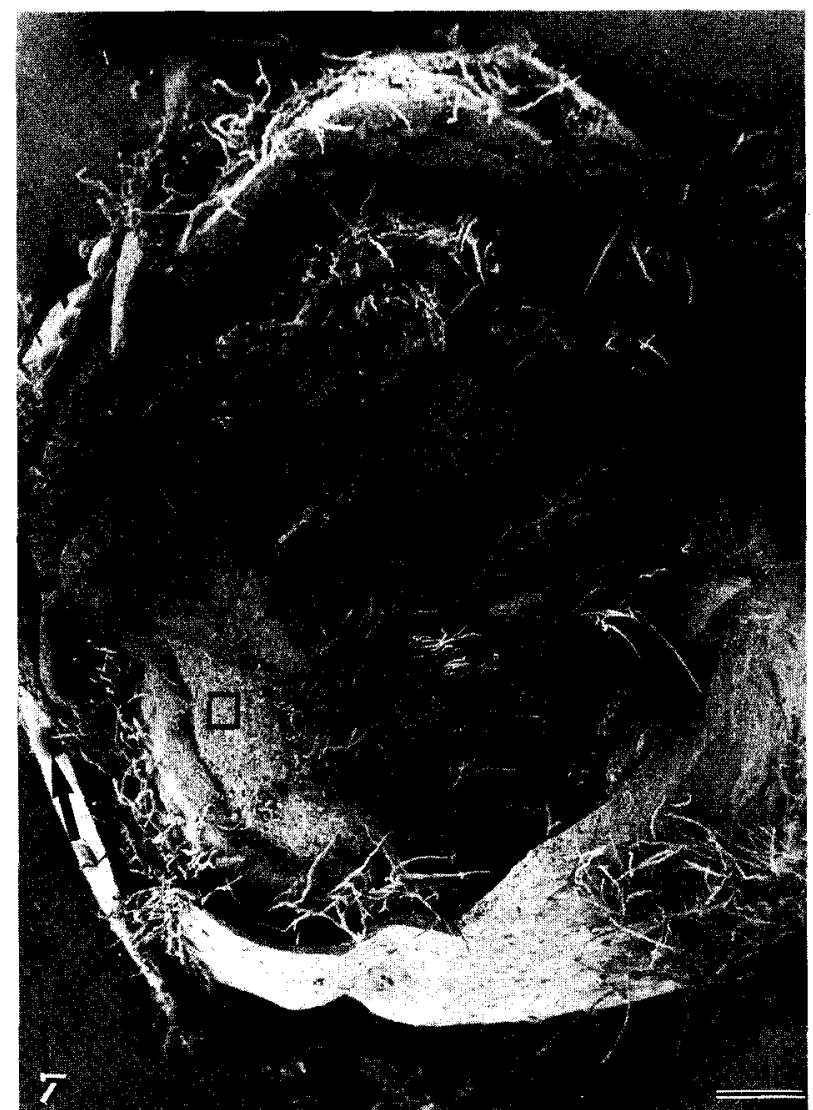

Fig. 7. Freeze-fractured image of a winter apple bud. Note the spider mite eggs on the surface of the outermost scale (arrows). The square frame represents the area illustrated in Fig. 8. Bar $=400 \mu \mathrm{m}$.

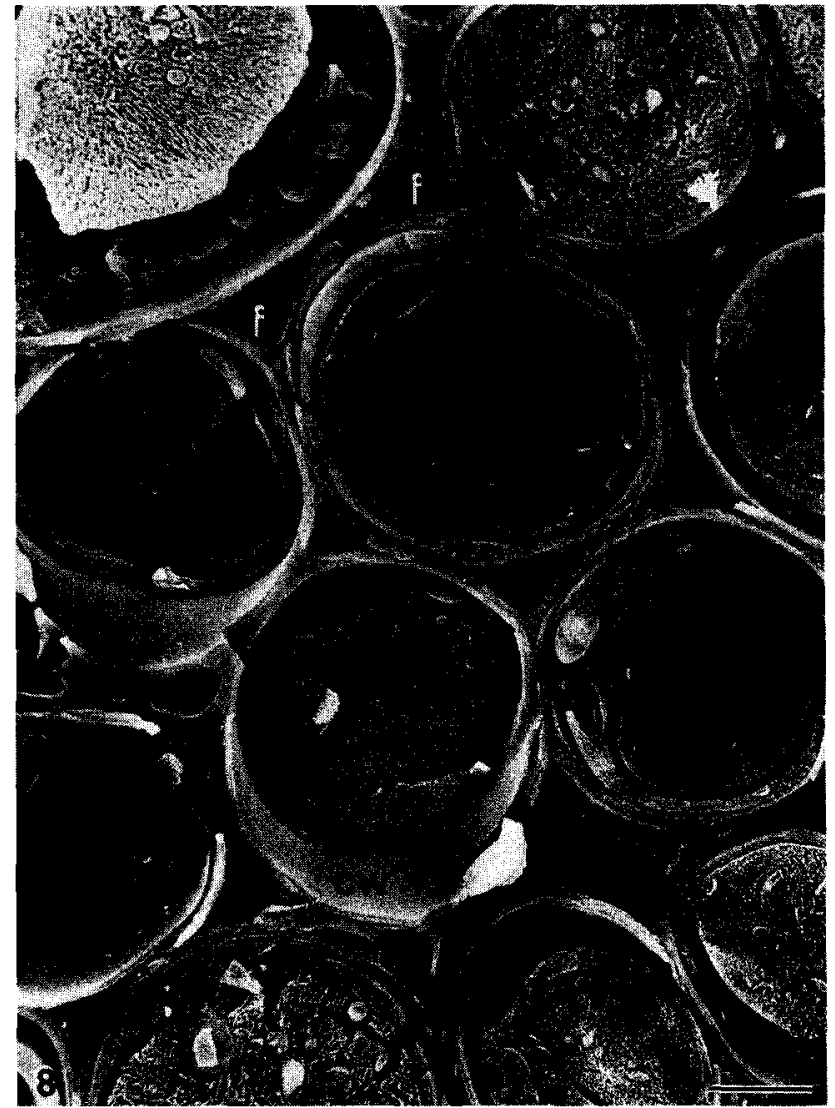

Fig. 8. Parenchyma cells of a freeze-fractured bud scale. Organelles (arrows) are visible. Although some cells exhibit freezing damage, the ice crystals are much smaller than those shown in Figs. 5 and 6. Perhaps a higher sugar content in winter acts as a cryoprotectant. cw, Cell wall; $\mathrm{i}$, intercellular space; $\mathrm{v}=$ vacuole. $\mathrm{Bar}=5 \mu \mathrm{m}$.

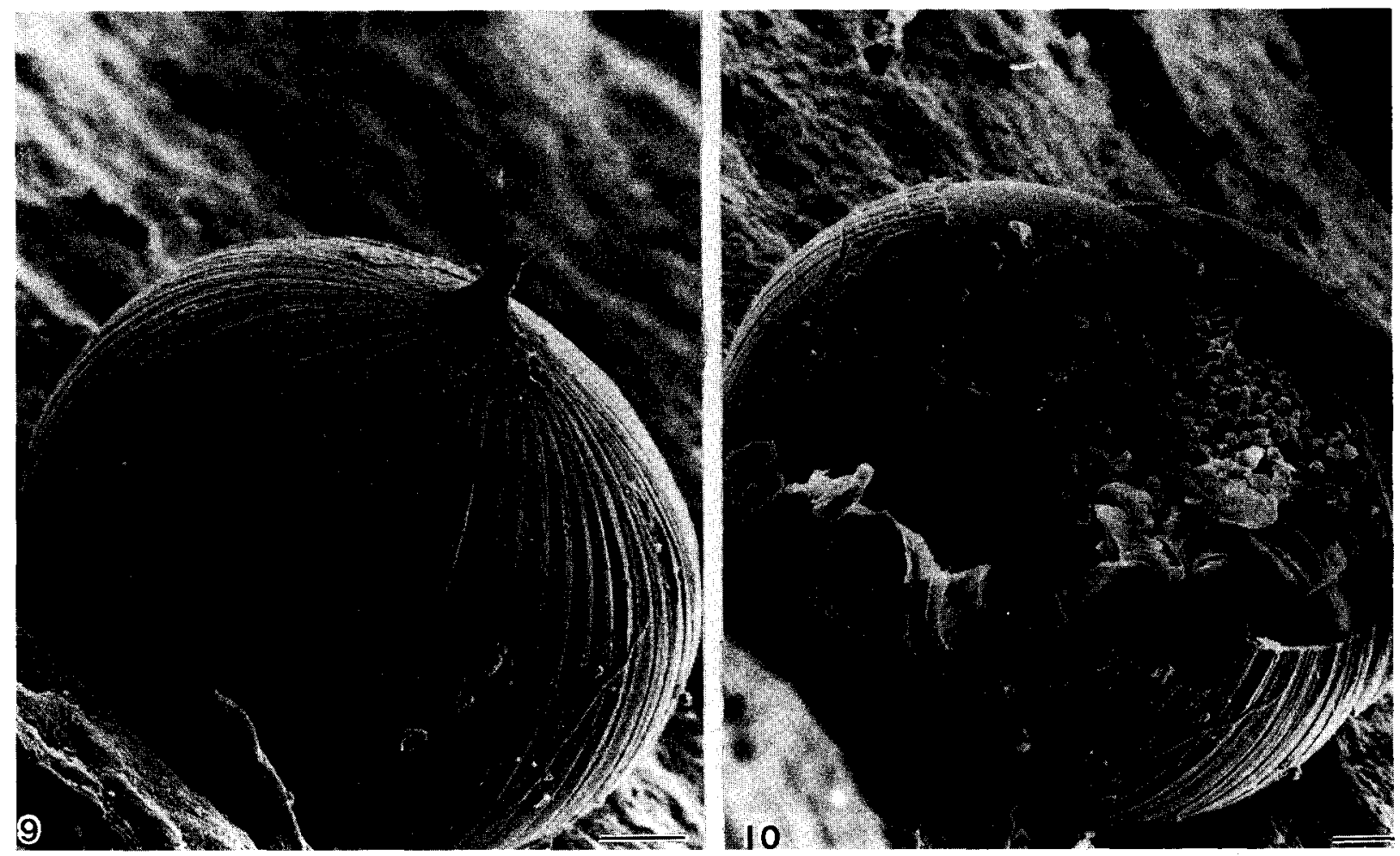

Figs. 9-10. Spider mite egg on the surface of apple bud scale. After the egg was photographed (Fig. 9), the frozen specimen was transferred from the microscope to the cryochamber where it was fractured with a pick. Following this procedure, the specimen was reinserted into the microscope and rephotographed (Fig 10). This approach allows observation of intact surface structure as well as fractured internal tissue of the same specimen. Bar $=20 \mu \mathrm{m}$. 
samples than conventionally dried samples because any water or oil vapors in the cryosystem or microscope will condense on the cold surface of the sample. Water ice is the major contaminant on the frozen specimen and can be easily removed by raising the temperature of the specimen above $-100 \mathrm{C}$ to sublime the ice. Finally, ice crystal damage occurs during freezing and is most pronounced in fractured images of highly hydrated tissues, such as parenchyma cells (Figs. 5 and 6). Although we have not attempted to prevent ice formation in this study, using other cryogens, cryoprotectants, and alternate freezing methods, such as "slam freezing" (cold metal block freezing) or high-pressure freezing (Gilkey and Staehelin, 1986), can reduce or eliminate ice crystal damage that may interfere with a particular study. Ice crystals also form in plant material under naturally occurring conditions and are at least partially responsible for winter kill. Improvements in low-temperature field emission SEM currently allow investigators to resolve structural features $<10 \mathrm{~nm}$ in diameter. Perhaps this technique will soon allow investigators to observe winter kill at the ultrastructural level.

\section{Literature Cited}

Beckett, A. and N.D. Read. 1986. Low-temperature scanning electron microscopy, p. 45-80. In: H.C. Aldrich and W.J. Todds (eds.). Ultrastructural techniques for microorganisms. Plenum, New York.

Ben-Arie, R., N. Kislev, and C. Frenkel. 1979. Ultrastructural changes in the cell walls of ripening apple and pear fruit. Plant Physiol. 64:197202.

Bukovac, M.J., H.P. Rasmussen, and V.E. Shull. 1981. The cuticle: Surface, structure and func- tion. Scanning Electron Microscopy III:213223.

Crang, R.F.E. 1988. Artifacts in specimen preparation for scanning electron microscopy, p. 107129. In: R.F.E. Crang and K.L. Klomparens (eds.). Artifacts in biological electron microscopy. Plenum, New York.

Crookes, P.R. and D. Grierson. 1983. Ultrastructure of tomato fruit, ripening and the role polygalacturonase isoenzymes in cell wall degradation. Plant Physiol. 72:1088-1093.

Echlin, P., R. Paden, B. Dronzek, and R. Wayte. 1970. Scanning electron microscopy of labile biological material maintained under controlled conditions. Scanning Electron Microscopy 1970:49-56.

Faust, M. and C.B. Shear. 1972. Fine structure of the fruit surface of three apple cultivars. J. Amer. Soc. Hort. Sci. 97:351-355.

Gilkey, J.C. and L.A. Staehelin. 1986. Advances in ultrarapid freezing for the preservation of cellular ultrastructure. J. Electron Microsc. Tech. 3:177-210.

Glenn, G.M., B.W. Poovaiah, and H.P. Rasmussen. 1985. Pathways of calcium penetration through isolated cuticles of 'Golden Delicious' apple fruit. J. Amer. Soc. Hort. Sci. 110:166-171.

Jeffree, C.E. and N.D. Read. 1991. Ambient and low-temperature scanning electron microscopy, p. 313-414. In: J.L. Hall and C. Hawes (eds.). Electron microscopy of plant cells, Academic, London,

Kellenberger, E., R. Johansen, M. Maeder, B. Bohrmann, E. Stauffer, and W. Villiger. 1992. Artifacts and morphological changes during chemical fixation. J. Microsc. 168:181 -201.

Laval-Martin, D. 1974. La maturation du fruit de tomate cerise: Mise en évidence, par cryodécapage, de l'évolution des chloroplastes en deux types de chromoplastes. Protoplasm 82:35-59.

Littlefield, L.J. and M.C. Heath. 1979, Morphology and ontogeny of sori and spores, p. 3-91. In: Ultrastructure of rust fungi. Academic, New York.
Masia, A., A. Zanchin, N. Rascio, and A. Ramina. 1992. Some biochemical and ultrastractural aspects of peach fruit development. J. Amer. Soc, Hort. Sci. 117:808-815.

Read, N.D. and C.E. Jeffree. 1991, Low-temperature scanning electron microscopy in biology. J. Microsc. 161:59-72.

Steere, R.L. and E.F. Erbe. 1981. Hingeless complementary holders for the Denton freeze-etch apparatus, p. 564-565. In: G.W. Bailey (ed.). Proc. Electron Microsc, Soc. Amer. Claitor's Publishing Division, Baton Rouge, La.

Wergin, W.P. 1984. Importance of incorporating stereopsis and stereometry into a scanning electron microscope course. Scanning electron microscopy. 111:1225-1235.

Wergin, W.P. and E.F. Erbe. 1989, Increasing the versatility of an EMscope SP2000A sputter cryo system on a Hitachi S-570 scanning electron microscope. Scanning 11:293-303.

Wergin, W.P. and E.F. Erbe. 1991. Introduction to the advantages and problems associated with low temperature scanning electron microscopy. Scanning 13:24-26.

Wergin, W.P. and E.F. Erbe. 1992a. Techniques for obtaining and observing complementary images with a low-temperature field emission SEM and subsequent comparison of the identical cells in freeze-etch replicas viewed with a TEM. Scanning 14:17-30.

Wergin, W.P. and E.F. Erbe. 1992b. Recent advancements in low temperature scanning electron microscopy. Scanning (suppl.) 14:40-42.

Wergin, W.P. and C. Pooley. 1988. Photographic and interpretive artifacts, p. 175-204. In: R.F.E. Crang and K.L. Klomparens (eds.). Artifacts in biological electron microscopy. Plenum, New York.

Wergin, W.P., R.M. Sayre, and T.W. Reilly, 1988. Low-voltage field emission scanning electron microscopy applications in hematology, p. 420 421. In: G.W. Bailey (ed.). Proc. Electron Microsc. Soc. Amer. San Francisco Press, San Francisco. 